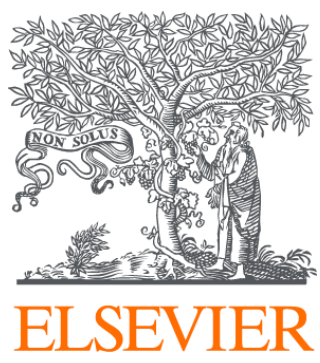

Since January 2020 Elsevier has created a COVID-19 resource centre with free information in English and Mandarin on the novel coronavirus COVID-

19. The COVID-19 resource centre is hosted on Elsevier Connect, the company's public news and information website.

Elsevier hereby grants permission to make all its COVID-19-related research that is available on the COVID-19 resource centre - including this research content - immediately available in PubMed Central and other publicly funded repositories, such as the WHO COVID database with rights for unrestricted research re-use and analyses in any form or by any means with acknowledgement of the original source. These permissions are granted for free by Elsevier for as long as the COVID-19 resource centre remains active. 


\title{
Do predictors of adherence to pandemic guidelines change over time? A panel study of 22,000 UK adults during the COVID-19 pandemic
}

\author{
Liam Wright ${ }^{\mathrm{b}, *}$, Daisy Fancourt ${ }^{\mathrm{a}}$ \\ ${ }^{a}$ Department of Behavioural Science and Health, University College London, WC1E 7HB, UK \\ ${ }^{\mathrm{b}}$ Institute of Education, University College London, WC1H ONU, UK
}

\section{A R T I C L E I N F O}

\section{Keywords:}

COVID-19

Compliance

Non-pharmaceutical interventions

\begin{abstract}
A B S T R A C T
In the absence of a vaccine, governments have focused on behaviour change (e.g. social distancing and enhanced hygiene procedures) to tackle the COVID-19 pandemic. Existing research on the predictors of compliance with pandemic measures has often produced discrepant results. One explanation for this may be that the determinants of compliance are context specific. Understanding whether this is the case is important for designing public health messaging and for evaluating the generalisability of existing research. We used data from the UCL COVID19 Social Study; a large weekly panel of UK adults from first five months of lockdown in the UK $(n=22,625)$. We tested whether the extent to which demographic, socio-economic position, personality traits, social and prosocial motivations, and the living environment predict compliance changed across the pandemic using multilevel regression modelling. Low compliance was strongly related to younger age and also to risk attitudes, empathic concern, and high income, among other factors. The size of some of these associations was larger in later months when less stringent lockdown and household mixing measures were in place. The results showed that compliance was lower and fell faster across some groups, suggesting the importance that public health communications adopt a plurality of messages to maximize broad adherence.
\end{abstract}

\section{Introduction}

Governments have implemented a range of measures to tackle the COVID-19 pandemic. In the absence of a vaccine, measures have focused on reducing transmission of the virus through isolating those with diagnosed or suspected COVID-19, increasing 'social distancing' (e.g. 'shelter-at-home' orders, restricting non-essential travel and limiting groups gathering in public venues), and enhancing hygiene procedures (such as the wearing of face masks). These measures are effective(Chu et al., 2020; Mongey et al., 2020) but require cooperation on the behalf of citizens. Ensuring high levels of compliance has been a challenge. (Fancourt et al., 2020; Park et al., 2020; Wang et al., 2020) Understanding the factors that determine compliance is vital for managing the pandemic.

There is a sizeable literature on the determinants of compliance with social distancing, hygiene, and quarantine rules, both from the COVID19 pandemic and from previous epidemics.(Bish and Michie, 2010; Perra, 2021; Webster et al., 2020) The literature highlights the importance of socio-economic and demographic characteristics (e.g. age,(Bish and Michie, 2010; Perra, 2021) gender,(Bish and Michie, 2010; Perra,
2021; Galasso et al., 2020) education(Bish and Michie, 2010; Perra, 2021) and working status(Bish and Michie, 2010; Webster et al., 2020; Papageorge et al., 2021)), personality traits (e.g. Big-5 traits(Zajenkowski et al., 2020; Blagov, 2020) and self-efficacy(Bish and Michie, 2010)), social and pro-social motivations (e.g. social norms,(Young and Goldstein, 2021) social capital(Jørgensen et al., 2021; Borgonovi and Andrieu, 2020) and empathic concern(Pfattheicher et al., 2020)), and the lived environment (such as household overcrowding(Patel et al., 2020) and availability of green space(Bonell et al., 2020; Heo et al., 2020)), in predicting compliance levels. The results in this literature are not always consistent, however. For instance, younger people,(Bish and Michie, 2010) males,(Bish and Michie, 2010; Perra, 2021) and more extroverted individuals(Zajenkowski et al., 2020; Brouard et al., 2020) are often found to have lower compliance than other individuals, but some studies show opposite or no effects.(Bish and Michie, 2010; Barber and Kim, 2020; Bogg and Milad, 2020)

One explanation for these discrepancies may be that the determinants of compliance are context-specific. For instance, self-efficacy beliefs, old age, and risk-preferences may change in importance as cases rise or as external restrictions on behaviour change. This is consistent

\footnotetext{
* Corresponding author at: 55-59 Gordon Square, London WC1H 0NU, UK.

E-mail address: liam.wright.17@ucl.ac.uk (L. Wright).
} 
with models of human behaviour such as the "COM-B" framework, which posits that capabilities, opportunities and motivations combine to determine behaviour.(Michie et al., 2011) For example, low self-efficacy may undermine psychological capability and risk-preferences and age may factor into non-compliance motivations, but strict lockdown may limit opportunities for non-compliance. Strict lockdown may thus represent a "strong situation" where opportunities for non-compliance are restricted and the information regarding desired behaviour is clear, making personality and other characteristics less important for compliance behaviour.(Zajenkowski et al., 2020; Götz et al., 2020)

This argument is supported by findings from the H1N1 pandemic that the predictors of compliance differed through time.(van der Weerd et al., 2011) It is also supported by findings from the COVID-19 pandemic that the Big-5 personality traits neuroticism and openness were more highly related to compliance with "shelter-at-home" guidelines in areas where less stringent measures were in place.(Götz et al., 2020) Overall compliance levels do not remain stable across epidemics, (Cowling et al., 2010; YouGov, 2021; de Zwart et al., 2010; Raude et al., 2019; Springborn et al., 2015; Bierwiaczonek et al., 2020) which raises the possibility that the composition of non-complying groups varies through time. Together, this suggests that existing COVID-19 studies which have typically used cross-sectional data from the early months of the pandemic(Clark et al., 2020; Harper et al., 2020; Painter and Qiu, 2020) - may not be generalisable across the full pandemic. Changes in the determinants of compliance may have implications for the targeting and phrasing of public health messaging and design of measures to maintain or improve compliance as pandemics proceed.

Therefore, in this study, we sought to test whether the association between factors relating to demographic and socio-economic characteristics, personality traits and pro-social motivations were more or less predictive of compliance with COVID-19 guidelines across five months of the pandemic in the UK. We used data from a weekly balanced panel of over 22,000 adults across the period 01 April - 31 August 2020, during which time the stringency of lockdown measures in the devolved nations of the UK changed.(Hale et al., 2020) More detail on the change in government policy is provided in the methods section.

\section{Methods}

\subsection{Participants}

We used data from the COVID-19 Social Study; a large panel study of the psychological and social experiences of over 50,000 adults (aged $18+$ ) in the UK during the COVID-19 pandemic. The study commenced on 21 March 2020 and involved online weekly data collection across the pandemic in the UK. The sampling is not random and therefore is not representative of the UK population, but it does contain a heterogeneous sample. The sample was recruited using three primary approaches. First, snowballing was used, including promoting the study through existing networks and mailing lists (including large databases of adults who had previously consented to be involved in health research across the UK), print and digital media coverage, and social media. Second, more targeted recruitment was undertaken focusing on (i) individuals from a low-income background, (ii) individuals with no or few educational qualifications, and (iii) individuals who were unemployed. Third, the study was promoted via partnerships with third sector organisations to vulnerable groups, including adults with pre-existing mental health conditions, older adults, carers, and people experiencing domestic violence or abuse. The study was approved by the UCL Research Ethics Committee [12,467/005] and all participants gave informed consent. The study protocol and user guide (which includes full details on recruitment, retention, data cleaning, weighting and sample demographics) are available at https://github.com/UCL-BSH/CSSUserGui de.

For these analyses, we focused on participants with data collection in each month between 01 April - 31 August $(n=23,252$, observations =
$427,161)$. Recruitment into the study was ongoing across this period. This sample represents $38.8 \%$ of those who participated by 30 April 2020. We excluded participants with missing data on key demographic data that we use to construct survey weights ( $n=627$, observations $=$ 11,480 ). We used complete case analysis as (a) there was only a small amount of item missingness in the study and (b) item missingness was dictated by not having data collection during limited periods in which particular questions were included in the survey, which suggests data are missing at random.

\subsection{Lockdown measures}

National lockdown was announced on 23 March 2020. Residents were required to stay at home unless purchasing essential items, exercising in nearby outdoor locations (at most once a day), or helping vulnerable individuals. Public venues were closed and businesses operated with strict social distancing guidelines or using remote working, where possible. Restrictions were gradually reduced from May 2020 with variation across the devolved nations in both the timing and extent of the reduction.(Cameron-Blake et al., 2020) Domestic travel limits were removed from 13 May in England but were relaxed later in Northern Ireland (26 June), Wales (6 July), and Scotland (7 July). Restrictions on indoor and outdoor household mixing were also gradually reduced (in June in England and Northern Ireland and July in Wales and Scotland), though local lockdowns were subsequently imposed in higher transmission areas of the UK from July. In the latter months, the UK government passed laws making face masks compulsory in public places and also began actively encouraging citizens to return to workplaces and to public venues - for instance, in August, running a subsidized meal scheme ("Eat Out to Help Out") to support the restaurant sector. See Supplementary Fig. 1.

\subsection{Measures}

\subsubsection{Compliance with COVID-19 guidelines}

Compliance with guidelines was measured weekly using a singleitem measure: "Are you following the recommendations from authorities to prevent spread of Covid-19?". The item was measured on a seven-point Likert scale ( 1 = "Not at all", 7 = "Very much so"), and analysed as a continuous variable.

While this measure asks about compliance in general rather than referring to specific behaviours, it is related to items on specific compliance behaviours (mask wearing, social distancing, etc.) that have been collected at later time-points in the COVID-19 Social Study (see Supplementary Information).

\subsubsection{Predictors of compliance}

To assess socioeconomic and demographic predictors of compliance, we included the demographic variables for country of residence, sex, ethnicity (White or Non-White) and age (grouped). We also included variables for socio-economic position (SEP): annual income (grouped), education level, employment status, household overcrowding $(<1$ person per room, $1+$ persons per room), and living arrangement (alone, with child; alone, no child; not alone, no child; not alone, with child). Each were measured at baseline data collection.

To assess predictors related to personality traits, we included Big Five personality traits (openness, conscientiousness, extraversion, agreeableness, and neuroticism),(Soto and John, 2017) resilience, (Smith et al., 2008) locus of control,(Hirschman and Almgren, 2012) optimism,(Scheier et al., 1994) and risk-taking.(Dohmen et al., 2011) Big Five traits were measured at baseline data collection, while other traits were measured at during follow-up. More detail on the measurement of the variables in this analysis is included in the Supplementary Information.

To assess social and prosocial factors, we included measures of emotional and cognitive empathy, neighbourhood social capital, 
neighbourhood attachment, neighbourhood satisfaction,(Peck, 1981) available neighbourhood space and neighbourhood crowding. Each of these variables were collected during follow-up. Neighbourhood social capital items referred to the period before COVID-19. Our hypothesis was that prosocial motivations would increase compliance, and that strong attachment or belonging to local neighbourhoods would increase these motivations as well as increasing the likelihood that individuals would be aware of - and pay attention to - injunctive social norms to comply with guidelines.

\subsection{Statistical analysis}

Our basic empirical strategy was to estimate 2-level multilevel models of the form:

Comply $_{i t}=\beta_{0 i}+\beta_{1} \bullet$ Month $_{i t}+\beta_{2} \bullet$ Month $_{i t} \bullet$ Predictor $_{i}+\beta_{K} \bullet$ Month $_{i t} \bullet X_{i K}+\varepsilon_{i t}$

$\beta_{0 i}=\beta_{0}+\mu_{i}$

where $i$ is an index of individuals and $t$ is an index of time. $\mu_{i}$ is a personspecific random error (i.e. a random intercept) and $\varepsilon_{i t}$ is an observationspecific random error, both normally distributed. $M o n t h h_{i t}$ is a categorical indicator of the month the data was collected in, Predictor $_{i}$ is the (timeinvariant) predictor under study, and $X_{i K}$ is a set of control variables (defined below). Our interest is in the coefficients $\beta_{2}$, which shows how the between-person association between the predictor and compliance differ across time.

For each predictor variable, we estimated two models: an unadjusted model with no control variables (except month), and an adjusted model that included (i) factors we identified as core confounders (including demographic and socio-economic variables as defined above, preexisting psychiatric diagnosis, and Big-5 personality traits) and (ii) factors likely to account for differences in compliance behaviours (including self or family member "shielding" at any point due to preexisting health conditions, whether the participant was remaining indoors for other pre-existing health reasons (e.g. physical disability), and the number of long-term physical health conditions (categorical: 0,1 , $2+$ ). The definition of these measures in provided in the Supplementary Information. We used complete case data and survey weights when estimating models. Derivation of the survey weights is described in further detail in the Supplementary Information. For comparability, we report standardized coefficients.

An issue with restricting the analysis to individuals with data collection each month is that results may be biased by non-random attrition from the survey. In particular, individuals who report high compliance with COVID-19 guidelines are less likely to drop out (see Supplementary Information Fig. S2), which may bias towards finding smaller associations. Consequently, as a sensitivity analysis, we repeat models using data from balanced panels with fewer months of data.

\subsection{Role of the funding source}

The funders had no final role in the study design; in the collection, analysis and interpretation of data; in the writing of the report; or in the decision to submit the paper for publication. All researchers listed as authors are independent from the funders and all final decisions about the research were taken by the investigators and were unrestricted.

\section{Results}

\subsection{Descriptive statistics}

Descriptive statistics for the sample are displayed in Table 1. Participants are disproportionately female, middle-aged (age 46-59), highly educated, white, and from Wales.

While compliance levels were high overall, there was a statistically
Table 1

Descriptive statistics.

\begin{tabular}{|c|c|c|c|}
\hline & Variable & Unweighted & Weighted \\
\hline & $\mathrm{n}$ & 22,625 & 22,625 \\
\hline \multirow[t]{4}{*}{ Age (grouped) } & $60+$ & $\begin{array}{l}10,035 \\
(44.35 \%)\end{array}$ & $\begin{array}{l}11,679.69 \\
(51.62 \%)\end{array}$ \\
\hline & $46-59$ & $\begin{array}{l}7144 \\
(31.58 \%)\end{array}$ & $\begin{array}{l}5799.04 \\
(25.63 \%)\end{array}$ \\
\hline & $30-45$ & $\begin{array}{l}4521 \\
(19.98 \%)\end{array}$ & $\begin{array}{l}3632.15 \\
(16.05 \%)\end{array}$ \\
\hline & $18-29$ & $925(4.09 \%)$ & $\begin{array}{l}1514.13 \\
(6.69 \%)\end{array}$ \\
\hline \multirow[t]{2}{*}{ Gender } & Female & $\begin{array}{l}16,741 \\
(73.99 \%)\end{array}$ & $\begin{array}{l}11,111.33 \\
(49.11 \%)\end{array}$ \\
\hline & Male & $\begin{array}{l}5884 \\
(26.01 \%)\end{array}$ & $\begin{array}{l}11,513.67 \\
(50.89 \%)\end{array}$ \\
\hline \multirow[t]{2}{*}{ Ethnicity } & White & $\begin{array}{l}21,882 \\
(96.72 \%)\end{array}$ & $\begin{array}{l}21,116.39 \\
(93.33 \%)\end{array}$ \\
\hline & Non-white & $743(3.28 \%)$ & $\begin{array}{l}1508.61 \\
(6.67 \%)\end{array}$ \\
\hline \multirow[t]{4}{*}{ Country } & Scotland & $1441(6.37 \%)$ & $\begin{array}{l}1822.22 \\
(8.05 \%)\end{array}$ \\
\hline & England & $\begin{array}{l}17,551 \\
(77.57 \%)\end{array}$ & $\begin{array}{l}18,624.75 \\
(82.32 \%)\end{array}$ \\
\hline & Wales & $\begin{array}{l}3413 \\
(15.09 \%)\end{array}$ & $\begin{array}{l}1742.84 \\
(7.7 \%)\end{array}$ \\
\hline & Northern Ireland & $220(0.97 \%)$ & $\begin{array}{l}435.18 \\
(1.92 \%)\end{array}$ \\
\hline \multirow[t]{3}{*}{ Education } & GCSE or below & $\begin{array}{l}3230 \\
(14.28 \%)\end{array}$ & $\begin{array}{l}7494.49 \\
(33.12 \%)\end{array}$ \\
\hline & A-level & $\begin{array}{l}3908 \\
(17.27 \%)\end{array}$ & $\begin{array}{l}7271.22 \\
(32.14 \%)\end{array}$ \\
\hline & Degree or above & $\begin{array}{l}15,487 \\
(68.45 \%)\end{array}$ & $\begin{array}{l}7859.29 \\
(34.74 \%)\end{array}$ \\
\hline \multirow[t]{5}{*}{ Household income } & $<£ 16 \mathrm{k}$ & $\begin{array}{l}3106 \\
(15.27 \%)\end{array}$ & $\begin{array}{l}4099.51 \\
(20.3 \%)\end{array}$ \\
\hline & $£ 16 \mathrm{k}-£ 30 \mathrm{k}$ & $\begin{array}{l}5417 \\
(26.63 \%)\end{array}$ & $\begin{array}{l}6271.51 \\
(31.06 \%)\end{array}$ \\
\hline & $£ 30 \mathrm{k}-£ 60 \mathrm{k}$ & $\begin{array}{l}7116 \\
(34.98 \%)\end{array}$ & $\begin{array}{l}6394.21 \\
(31.67 \%)\end{array}$ \\
\hline & $£ 60 \mathrm{k}-£ 90 \mathrm{k}$ & $\begin{array}{l}2823 \\
(13.88 \%)\end{array}$ & $\begin{array}{l}2124.96 \\
(10.52 \%)\end{array}$ \\
\hline & $£ 90 \mathrm{k}+$ & $1881(9.25 \%)$ & $\begin{array}{l}1300.31 \\
(6.44 \%)\end{array}$ \\
\hline \multirow[t]{4}{*}{ Economic activity } & Retired & $\begin{array}{l}7554 \\
(33.39 \%)\end{array}$ & $\begin{array}{l}8618.23 \\
(38.09 \%)\end{array}$ \\
\hline & Employed & $\begin{array}{l}12,417 \\
(54.88 \%)\end{array}$ & $\begin{array}{l}10,677.94 \\
(47.2 \%)\end{array}$ \\
\hline & Student & $477(2.11 \%)$ & $\begin{array}{l}785.86 \\
(3.47 \%)\end{array}$ \\
\hline & Unemployed/inactive & $2177(9.62 \%)$ & $\begin{array}{l}2542.97 \\
(11.24 \%)\end{array}$ \\
\hline \multirow[t]{4}{*}{ Living arrangement } & Not alone, no child & $\begin{array}{l}13,299 \\
(58.78 \%)\end{array}$ & $\begin{array}{l}13,987.61 \\
(61.82 \%)\end{array}$ \\
\hline & Not alone, with child & $3891(17.2 \%)$ & $\begin{array}{l}3280.05 \\
(14.5 \%)\end{array}$ \\
\hline & Alone, no child & $\begin{array}{l}4990 \\
(22.06 \%)\end{array}$ & $\begin{array}{l}5014.07 \\
(22.16 \%)\end{array}$ \\
\hline & Alone, with child & $445(1.97 \%)$ & $\begin{array}{l}343.27 \\
(1.52 \%)\end{array}$ \\
\hline \multirow[t]{13}{*}{ Overcrowding } & $<1$ persons per room & $\begin{array}{l}21,085 \\
(93.19 \%)\end{array}$ & $\begin{array}{l}20,616.22 \\
(91.12 \%)\end{array}$ \\
\hline & $1+$ person per room & $1540(6.81 \%)$ & $\begin{array}{l}2008.78 \\
(8.88 \%)\end{array}$ \\
\hline & Low openness & $8.68(3.24)$ & $9.17(3.25)$ \\
\hline & Low conscientiousness & $7.93(2.89)$ & $8.14(2.94)$ \\
\hline & Extraversion & $12.79(4.27)$ & $12.59(4.25)$ \\
\hline & Low agreeableness & $8.41(3.01)$ & $8.58(3.09)$ \\
\hline & Low neuroticism & $13.05(4.25)$ & $13.2(4.33)$ \\
\hline & Low resilience & $15.58(5.15)$ & 15.35 \\
\hline & Low optimism & $16.14(4.68)$ & $16.62(4.7)$ \\
\hline & $\begin{array}{l}\text { External locus of } \\
\text { control }\end{array}$ & $12.21(2.63)$ & $12.47(2.69)$ \\
\hline & Risk-taking & $4.37(2.34)$ & $4.35(2.42)$ \\
\hline & Low cognitive empathy & $9.28(4.83)$ & $10.01(4.99)$ \\
\hline & $\begin{array}{l}\text { Low emotional } \\
\text { empathy }\end{array}$ & $7.27(4.65)$ & $8(4.82)$ \\
\hline
\end{tabular}

(continued on next page) 
Table 1 (continued)

\begin{tabular}{|c|c|c|c|}
\hline & Variable & Unweighted & Weighted \\
\hline & $\mathrm{n}$ & 22,625 & 22,625 \\
\hline & Low social capital & $12.97(3.46)$ & 13.15 (3.59) \\
\hline & $\begin{array}{l}\text { Attachment to } \\
\text { neighbourhood }\end{array}$ & 7.09 (3.23) & $7.24(3.34)$ \\
\hline & $\begin{array}{l}\text { Low neighbourhood } \\
\text { satisfaction }\end{array}$ & $1.9(0.92)$ & $1.97(0.94)$ \\
\hline & Available space & $3.58(1.13)$ & 3.65 (1.17) \\
\hline & $\begin{array}{l}\text { Neighbourhood } \\
\text { crowding }\end{array}$ & $4.96(1.85)$ & $5.01(1.83)$ \\
\hline \multirow[t]{2}{*}{$\begin{array}{l}\text { Shielding (pre- } \\
\text { existing condition) }\end{array}$} & No & $\begin{array}{l}18,024 \\
(79.66 \%)\end{array}$ & $\begin{array}{l}17,263.31 \\
(76.3 \%)\end{array}$ \\
\hline & Yes & $\begin{array}{l}4601 \\
(20.34 \%)\end{array}$ & $\begin{array}{l}5361.69 \\
(23.7 \%)\end{array}$ \\
\hline \multirow[t]{2}{*}{$\begin{array}{l}\text { Shielding (family } \\
\text { member) }\end{array}$} & No & $\begin{array}{l}19,678 \\
(86.97 \%)\end{array}$ & $\begin{array}{l}19,437.56 \\
(85.91 \%)\end{array}$ \\
\hline & Yes & $\begin{array}{l}2947 \\
(13.03 \%)\end{array}$ & $\begin{array}{l}3187.44 \\
(14.09 \%)\end{array}$ \\
\hline \multirow[t]{2}{*}{$\begin{array}{l}\text { Home for other } \\
\text { reason }\end{array}$} & No & $\begin{array}{l}21,671 \\
(95.78 \%)\end{array}$ & $\begin{array}{l}21,419.2 \\
(94.67 \%)\end{array}$ \\
\hline & Yes & $954(4.22 \%)$ & $\begin{array}{l}1205.8 \\
(5.33 \%)\end{array}$ \\
\hline \multirow[t]{2}{*}{ Psychiatric condition } & No & $\begin{array}{l}19,156 \\
(84.67 \%)\end{array}$ & $\begin{array}{l}19,203.27 \\
(84.88 \%)\end{array}$ \\
\hline & Yes & $\begin{array}{l}3469 \\
(15.33 \%)\end{array}$ & $\begin{array}{l}3421.73 \\
(15.12 \%)\end{array}$ \\
\hline \multirow[t]{3}{*}{ Long-term conditions } & 0 & $\begin{array}{l}12,697 \\
(56.12 \%)\end{array}$ & $\begin{array}{l}11,660.97 \\
(51.54 \%)\end{array}$ \\
\hline & 1 & $\begin{array}{l}6342 \\
(28.03 \%)\end{array}$ & $\begin{array}{l}6493.88 \\
(28.7 \%)\end{array}$ \\
\hline & $2+$ & $\begin{array}{l}3586 \\
(15.85 \%)\end{array}$ & $\begin{array}{l}4470.15 \\
(19.76 \%)\end{array}$ \\
\hline
\end{tabular}

significant decline in compliance with COVID-19 guidelines across the study period (Fig. 1). When comparing descriptive statistics and compliance levels according to last month of data collection in the study, participants who were included in the main analysis (i.e. data collection up to August 2020) had higher and less steep drops in compliance, were older, less likely to be employed, and differed on several personality traits, including higher optimism and resilience and lower neuroticism and openness to experience (Table S1 and Supplementary Fig. S2). Repeated cross-sectional data from YouGov(YouGov, 2021) on the performance of specific preventative behaviours showed declines in avoiding crowds and social gatherings between April and August, while mask-wearing and hand-washing increased (Supplementary Fig. S3).
Age-group, employment status, county of residence, income group, gender, living arrangement and household overcrowding were each related to compliance in multivariate models (Fig. 2; bivariate results, which are substantively similar, are shown in Supplementary Fig. S4.) Younger adults had lower levels of compliance than older adults in April and these age-related differences grew considerably as the pandemic continued. Females reported higher compliance than males, though there was little difference by month. There was little difference by ethnic group, but there was evidence that compliance was higher in Scotland than in England, to a somewhat greater extent in August than April/ May. There was also an association between higher education and higher household income and lower compliance that grew across time. Students and individuals in employment had lower compliance levels than retired individuals. Comparing students and retirees, the difference was larger in later months. Adults living with a child or in overcrowded accommodation had lower compliance rates, with this increasing over the summer months. Effect sizes were generally small $(<0.25 \mathrm{SD})$, except for age in latter months: by August, 18-29 year olds had 0.72 SD $(95 \% \mathrm{CI}=0.66,0.79)$ lower compliance than participants aged $60+$.

Each of the Big-5 traits, resilience, low optimism, locus of control, and risk tacking were related to compliance (Fig. 3; note the different scale used for the $\mathrm{x}$-axis). The strongest association was with risk taking, for which the association was almost twice as large in July/August than in April. Conscientiousness, openness to experience, and extraversion also become more highly related to compliance in later months, which low optimism became less strongly associated. Associations between compliance and agreeableness, resilience, locus of control and neuroticism were little changed. The bivariate results are substantively similar, except for extraversion, which was related to higher compliance (Supplementary Fig. S5). Effect sizes were small (less than approximately $0 \cdot 2$ $\mathrm{SD})$, in each case.

Lower empathy, neighbourhood attachment and social capital were each related to lower compliance (Fig. 4; note the different scale used for the x-axis). People with higher levels of cognitive or emotional empathy were more likely to continue complying in later months, while there was little change in associations for the other factors. Dissatisfaction with neighbourhood, available space and neighbourhood crowding were each related to lower compliance. The association between neighbourhood characteristics and compliance was broadly stable across time. Bivariate results are substantively similar, with the exception that there was no clear increase in the size of the association between low empathy and compliance in later months (Supplementary Fig. S6). Effect sizes

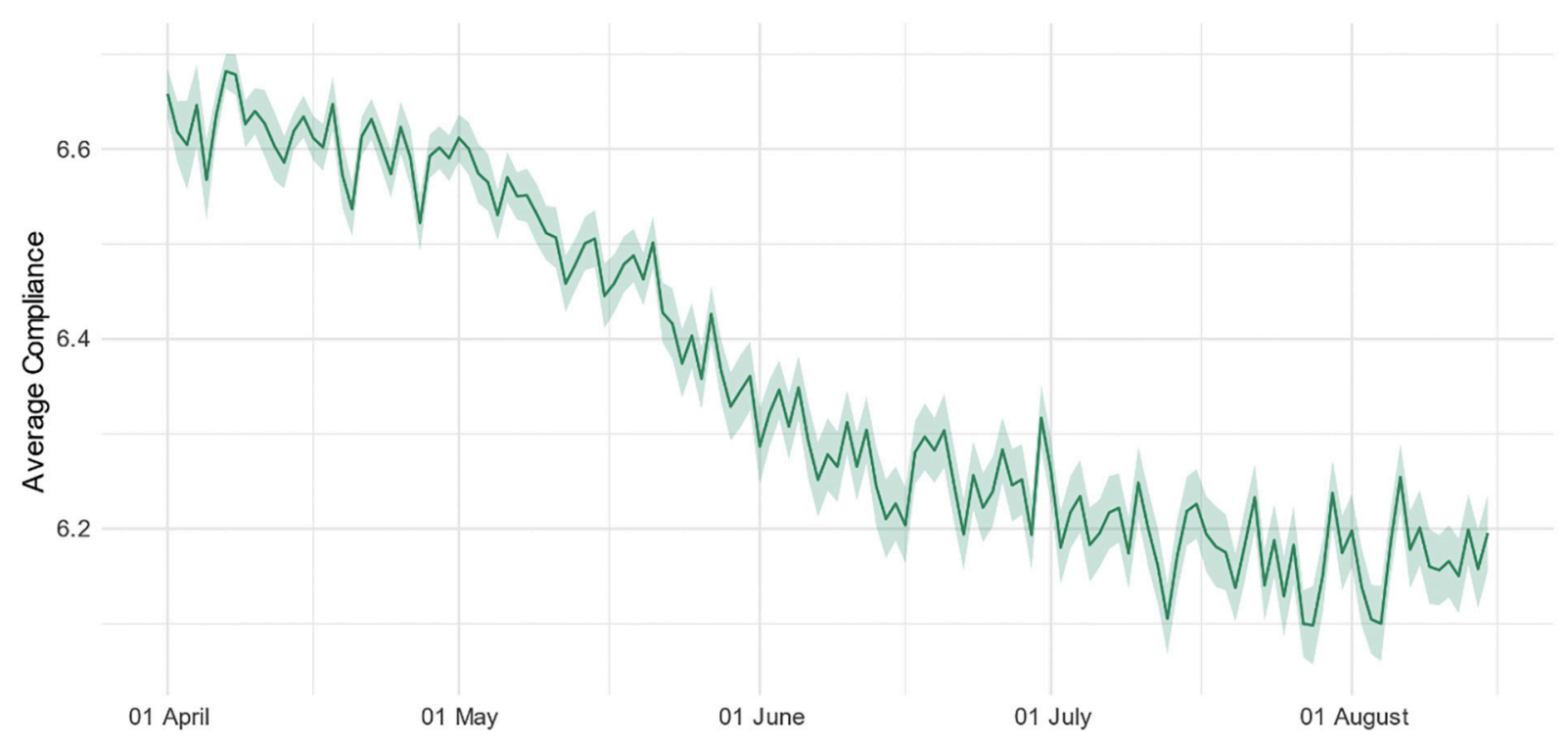

Fig. 1. (Weighted) daily average compliance with COVID-19 guidelines (+ 95\% CIs), 01 April - 15 August. 


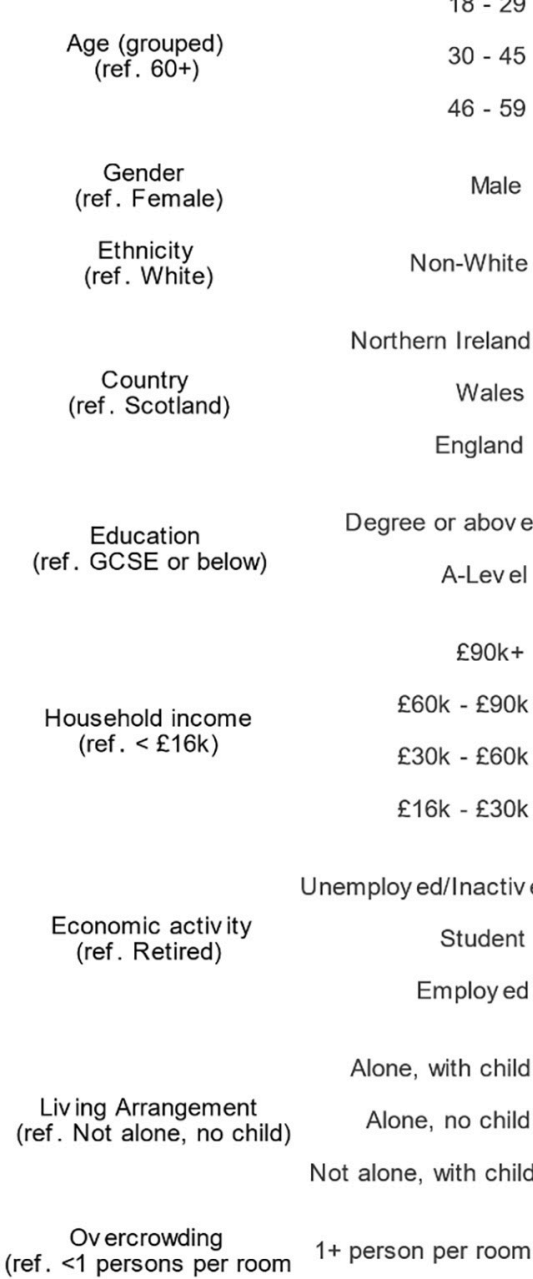

.
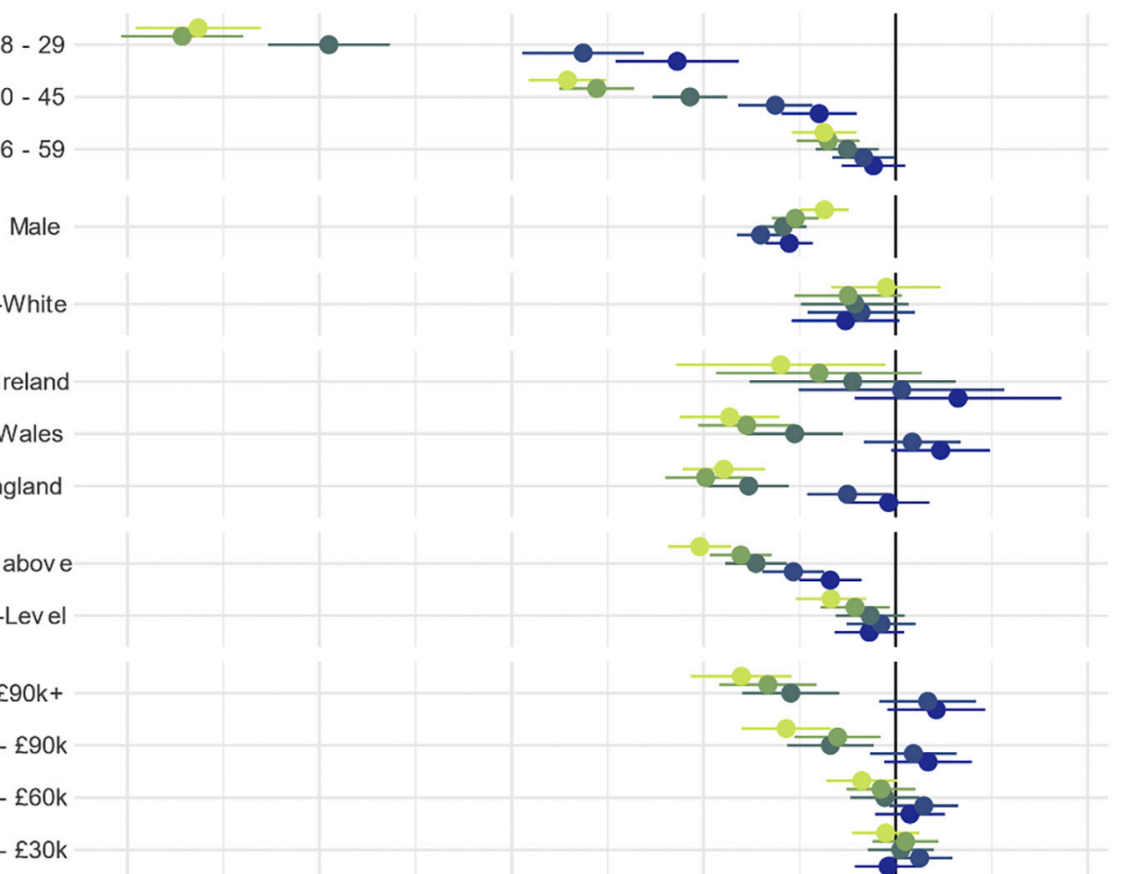


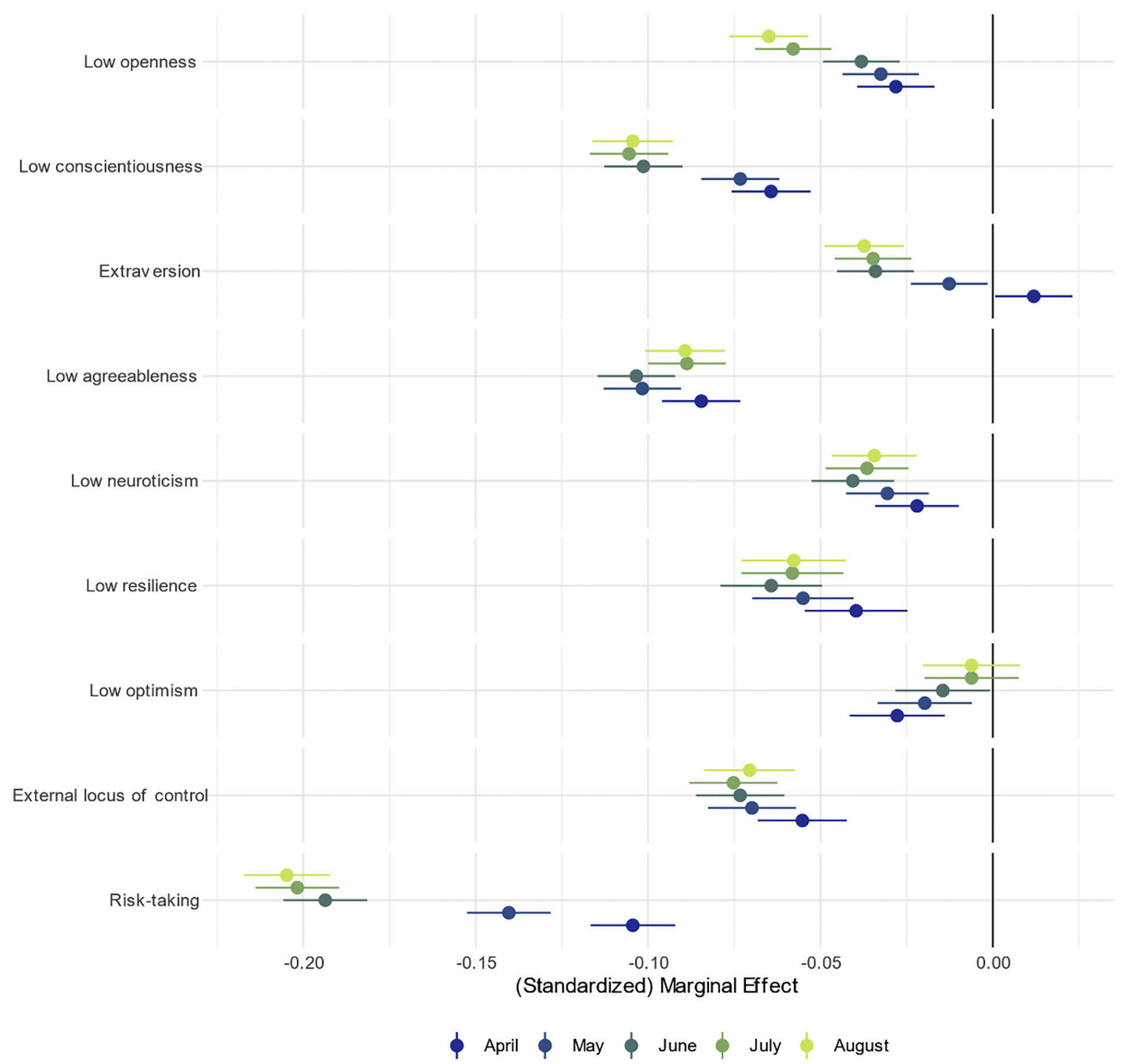

Fig. 3. Association between personality traits and compliance with COVID-19 guidelines by month, derived from mixed effects models. Left panel: bivariate association. Models include adjustment for sex, age group, ethnicity, education, income group, employment status, country of residence, living arrangement, household overcrowding, whether the participant is shielding, diagnosed psychiatric condition, long-term physical health conditions, and Big-5 personality traits.

compliance are context-specific. One explanation for these contextual differences is "situational strength", whereby behaviour is less determined by personal characteristics in contexts where options are constrained and/or normative behaviour is clearly prescribed.(Zajenkowski et al., 2020; Götz et al., 2020; Cooper and Withey, 2009) In support of this theory, decreases in average compliance coincided with lockdown and social distancing restrictions becoming less stringent. Indeed, we found that compliance decreased fastest in England and Wales (where restrictions were eased fastest) compared to Scotland (where restrictions were kept more stringent for longer).(Cameron-Blake et al., 2020) A further potential explanation for the differential strength of predictors is that as restrictions continued for longer, boredom increased and selfcontrol depleted, meaning that individuals' abilities to adhere to restrictive rules decreased and the predictive power of the studied factors became more evident.(Bieleke et al., 2020; Martarelli and Wolff, 2020) However, there were also other relevant changes over the period studied, which may have a bearing on results, including declining confidence in government(Fancourt et al., 2020; Wright et al., 2021) and changes in public health messaging (e.g. from "Stay at Home" to "Stay
Alert"). Nevertheless, this study highlights the importance of considering individual traits as evolving predictors of compliance and, in particular, considering the role of context as a moderator of the relationship between traits and compliance.

The results have a number of policy implications. First, the findings suggest that compliance with pandemic control measures decreases as the stringency of measures is reduced. This highlights the importance of reinforcing messaging on compliance as measures are eased to avoid perceptions that remaining measures are somehow unnecessary. Second, the results suggest some individuals may not be responsive to specific types of communications. For example, speculatively, individuals with high risk-taking propensities may be less responsive to messages about personal risk but more responsive to prosocial messages about the impact of their risk-taking on others. Therefore, in seeking to maximize compliance among different groups, a plurality of communication approaches may be required, though this would need to be balanced against the possibility of "alert fatigue".(Williams et al., 2020) The results also highlight why punitive measures for non-compliance may not be especially effective.(Kooistra et al., 2020; Murphy et al., 


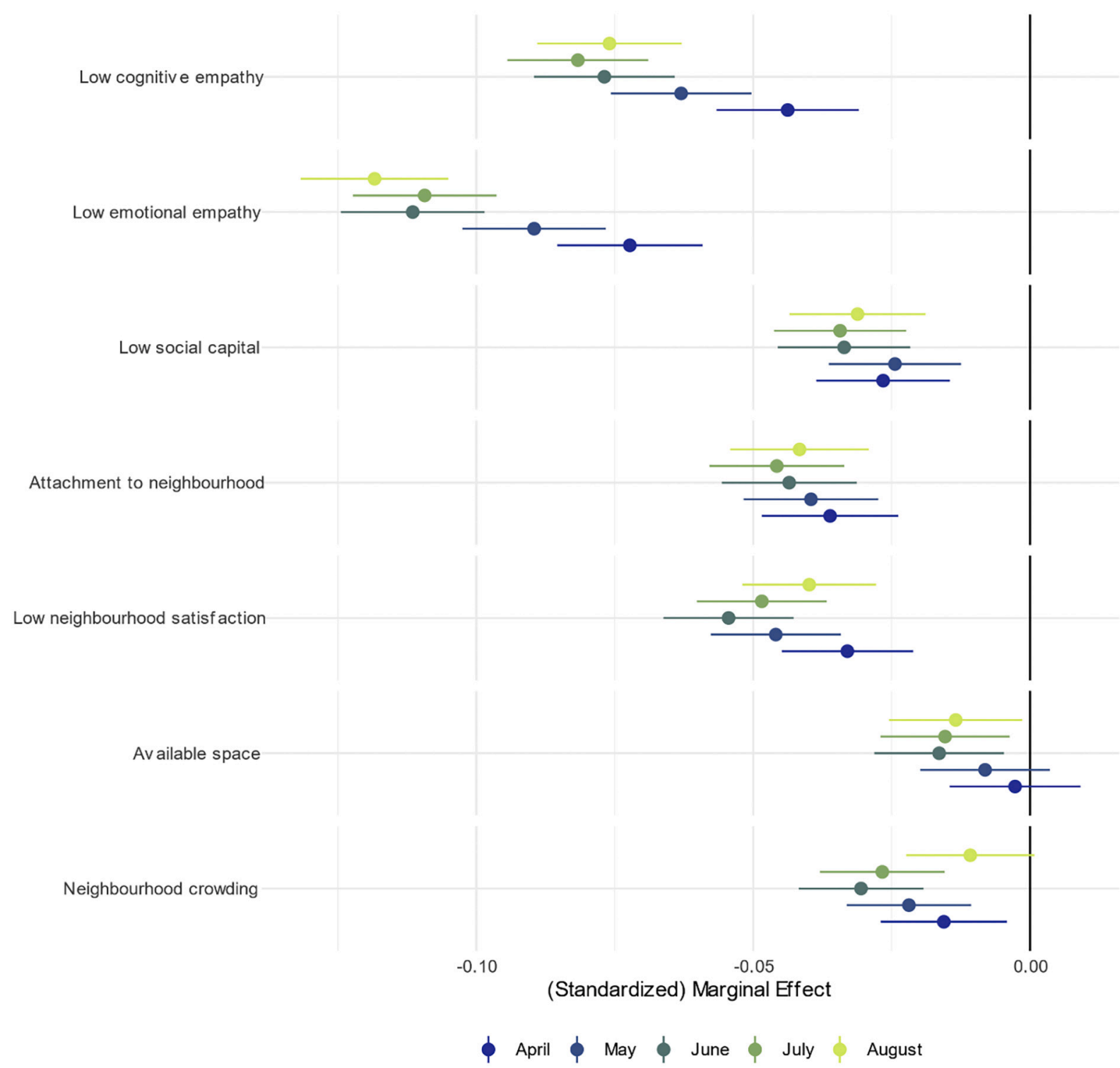

Fig. 4. Association between prosocial motivations, neighbourhood factors and compliance with COVID-19 guidelines by month, derived from mixed effects models. Models include adjustment for sex, age group, ethnicity, education, income group, employment status, country of residence, living arrangement, household overcrowding, whether the participant is shielding, diagnosed psychiatric condition, long-term physical health conditions, and Big-5 personality traits.

2020) For example, in September 2020, the UK government increased fines for those caught violating household mixing rules. Whilst such measures have the potential to reduce non-compliance among those for whom personal risk of infection or protecting others is not sufficient motivation, it risks reducing pro-social motivations(Gneezy and Rustichini, 2000) and highlighting the extent of norm violations, which, for some, could reduce compliance. Third, the finding that individuals living in overcrowded accommodation and neighbourhoods with little space had lower and faster decreasing compliance suggests that poor quality housing and crowded lived environments could exacerbate challenges for governments in tackling public health emergencies, over and above the greater risk of interpersonal transmission due to higher proximity.(Rader et al., 2020) Beside specific policies such as opening green spaces to improve compliance,(Bonell et al., 2020) tackling social inequalities more broadly may have consequences not only for general public health but also for behavioural management during pandemics.

That said, we also found that individuals with higher incomes had higher initial compliance but faster decreases over time. It is possible that these individuals were able to maintain a strict compliance initially due to not facing any financial barriers such as an inability to pay bills that may have driven to rules being broken in a search for work.(Wright et al., 2020) However, as the pandemic continued, it may be that greater wealth and a sense of privilege or a lack of financial fear over fines may have driven a more relaxed approach to compliance. Given research showing that the non-compliance of people in positions of power has a negative impact on societal trust and others' compliance,(Fancourt et al., 2020) this highlights the importance of the consistent application of pandemic rules among all groups.

This study had a number of limitations. Although we included a wide array of demographic and personality variables in our models, results may still have been explained by unobserved confounding. However, given that the strength of some of the factors studied here differed across the pandemic (e.g. risk taking), it is questionable how confounding factors could have generated these temporal patterns. Second, participants self-reported their compliance with measures. Results may, therefore, have been biased due to social desirability concerns and due to differences in knowledge or interpretation of the questionnaire item. People's understanding of compliance may also have differed over time, 
particular as rules changed. We lacked detail on the specific rules - such as mask-wearing, social distancing or hand-washing - that individuals were breaking when reporting lower compliance. Some of the factors studied here may be important for some behaviours rather than others for instance, extraversion is more plausibly related to violating social distancing rules than non-mask wearing. Further, bias may have arisen through the specifics of the guidelines differing through time. Notably, rules on mask wearing were introduced in the latter part of the study. As mask wearing is one of the most complied with behaviours (see Supplementary Fig. S3), the introduction of rules regarding masks may have reduced between-person differences in the latter stages of the study period: changes in particular behaviours according to person characteristics may be more pronounced than estimated here. Future studies are encouraged that explore specific compliance behaviours in more detail.

A third limitation is that we treated the predictors as fixed, but they may have varied over time - for instance, individual's empathy may have changed across the pandemic. This may have explained some of the time varying associations, though we note that associations with compliance were not always strongest in the month the predictors were measured in (see, for instance, Big 5 personality trait results). A final issue is the use of a non-random sample. While the sample was heterogeneous and we included population weights in models, the data were from a study set-up explicitly to research COVID-19. It is likely that individuals who participated (and continued to participate) in the study had a higher interest in helping tackle the pandemic than the general population at large. This interest may manifest as a higher propensity to comply with guidelines. Further, selection biases are likely to have arisen due to different modes of recruitment into the survey. Therefore, the relationships identified here may be biased estimates of the actual predictive effects of some of these factors.

\section{Conclusion}

This study demonstrated that the importance of many factors in predicting compliance has differed across the pandemic and is therefore context specific. Further, the results are in line with theories of "situational strength" where individual characteristics are more important where behaviour is less constrained. This highlights the need to account for context when studying compliance and to study predictors of compliance as evolving factors. For policy makers and public health professionals, the results suggest that if we want to maintain good compliance or increase compliance, two key things are needed. First, multiple messages are required to target different groups given capabilities and motivations will vary substantially between different demographic groups. Second, these messages will need to evolve across pandemics as the context and behavioural opportunities for individuals change.

\section{Data sharing statement}

Data from the COVID-19 Social Study will be made available at the end of the pandemic. The code to run the analyses in this paper is available at https://osf.io/e2c6g/.

\section{Author contributions}

Liam Wright: Conceptualization, Methodology, Formal analysis, Writing - original draft.

Daisy Fancourt: Conceptualization, Methodology, Writing - review \& editing, Funding Acquisition.

\section{Declaration of Competing Interest}

The authors have no interests to declare.

\section{Acknowledgments}

This Covid-19 Social Study was funded by the Nuffield Foundation [WEL/FR-000022583], but the views expressed are those of the authors and not necessarily the Foundation. The study was also supported by the MARCH Mental Health Network funded by the Cross-Disciplinary Mental Health Network Plus initiative supported by UK Research and Innovation [ES/S002588/1], and by the Wellcome Trust [221400/Z/ 20/Z]. DF was funded by the Wellcome Trust [205407/Z/16/Z]. The researchers are grateful for the support of a number of organisations with their recruitment efforts including: the UKRI Mental Health Networks, Find Out Now, UCL BioResource, SEO Works, FieldworkHub, and Optimal Workshop. The study was also supported by HealthWise Wales, the Health and Car Research Wales initiative, which is led by Cardiff University in collaboration with SAIL, Swansea University.

\section{Appendix A. Supplementary data}

Supplementary data to this article can be found online at https://doi. org/10.1016/j.ypmed.2021.106713.

\section{References}

Barber, S.J., Kim, H., 2020. COVID-19 worries and behavior changes in older and younger men and women. J. Gerontol. Ser. B 76 (2), e17-e23 gbaa068.

Bieleke, M., Martarelli, C., Wolff, W., 2020. Boredom makes it difficult, but it helps to have a plan: Investigating adherence to social distancing guidelines during the COVID-19 pandemic. PsyArXiv. https://doi.org/10.31234/osf.io/enzbv.

Bierwiaczonek, K., Kunst, J.R., Pich, O., 2020. Belief in COVID-19 conspiracy theories reduces social distancing over time. Appl. Psychol. Health Well-Being 12, 1270-1285.

Bish, A., Michie, S., 2010. Demographic and attitudinal determinants of protective behaviours during a pandemic: a review. Br. J. Health Psychol. 15, 797-824.

Blagov, P.S., 2020. Adaptive and dark personality in the COVID-19 pandemic: predicting health-behavior endorsement and the appeal of public-health messages. Soc. Psychol. Personal. Sci. 12 (5), 697-707, 194855062093643.

Bogg, T., Milad, E., 2020. Demographic, personality, and social cognition correlates of coronavirus guideline adherence in a U.S. sample. Health Psychol. 39, 1026-1036.

Bonell, C., Michie, S., Reicher, S., et al., 2020. Harnessing behavioural science in public health campaigns to maintain 'social distancing' in response to the COVID-19 pandemic: key principles. J. Epidemiol. Community Health 74, 617-619.

Borgonovi, F., Andrieu, E., 2020. Bowling together by bowling alone: social capital and COVID-19. Soc. Sci. Med. 265, 113501.

Brouard, S., Vasilopoulos, P., Becher, M., 2020. Sociodemographic and psychological correlates of compliance with the COVID-19 Public Health Measures in France. Can. J. Polit. Sci. 1-6.

Cameron-Blake, E., Tatlow, H., Wood, A., et al., 2020. Variation in the Response to COVID-19 across the Four Nations of the United Kingdom. Blavatnik School of Government, University of Oxford. https://www.bsg.ox.ac.uk/research/publications /variation-response-covid-19-across-four-nations-united-kingdom (accessed Nov 1, 2020).

Chu, D.K., Akl, E.A., Duda, S., et al., 2020. Physical distancing, face masks, and eye protection to prevent person-to-person transmission of SARS-CoV-2 and COVID-19: a systematic review and meta-analysis. Lancet 395, 1973-1987.

Clark, C., Davila, A., Regis, M., Kraus, S., 2020. Predictors of COVID-19 voluntary compliance behaviors: an international investigation. Glob. Trans. 2, 76-82.

Cooper, W.H., Withey, M.J., 2009. The strong situation hypothesis. Personal. Soc. Psychol. Rev. 13, 62-72.

Cowling, B.J., Ng, D.M.W., Ip, D.K.M., et al., 2010. Community psychological and behavioral responses through the first wave of the 2009 influenza a(H1N1) pandemic in Hong Kong. J. Infect. Dis. 202, 867-876.

de Zwart, O., Veldhuijzen, I.K., Richardus, J.H., Brug, J., 2010. Monitoring of risk perceptions and correlates of precautionary behaviour related to human avian influenza during 2006-2007 in the Netherlands: results of seven consecutive surveys. BMC Infect. Dis. 10, 114.

Dohmen, T., Falk, A., Huffman, D., Sunde, U., Schupp, J., Wagner, G.G., 2011. Individual risk attitudes: measurement, determinants, and behavioral consequences. J. Eur. Econ. Assoc. 9, 522-550.

Fancourt, D., Steptoe, A., Wright, L., 2020. The cummings effect: politics, trust, and behaviours during the COVID-19 pandemic. Lancet 396, 464-465.

Galasso, V., Pons, V., Profeta, P., Becher, M., Brouard, S., Foucault, M., 2020. Gender differences in COVID-19 attitudes and behavior: panel evidence from eight countries. PNAS 117, 27285-27291.

Gneezy, U., Rustichini, A., 2000. A fine is a Price. J. Leg. Stud. 29, 1-17.

Götz, F.M., Gvirtz, A., Galinsky, A.D., Jachimowicz, J.M., 2020. How personality and policy predict pandemic behavior: Understanding sheltering-in-place in 55 countries at the onset of COVID-19. Am. Psychol. https://doi.org/10.1037/amp0000740 published online Oct 15. 
Hale, T., Angrist, N., Cameron-Blake, E., et al., 2020. Oxford COVID-19 Government Response Tracker. Blavatnik School of Government, Oxford. https://www.bsg.ox.ac $\mathrm{uk} /$ research/research-projects/coronavirus-government-response-tracker (accessed Oct 22, 2020).

Harper, C.A., Satchell, L.P., Fido, D., Latzman, R.D., 2020. Functional fear predicts public health compliance in the COVID-19 pandemic. Int. J. Ment. Heal. Addict. https:// doi.org/10.1007/s11469-020-00281-5 published online April 27.

Heo, S., Lim, C.C., Bell, M.L., 2020. Relationships between local green space and human mobility patterns during COVID-19 for Maryland and California, USA. Sustainability $12,9401$.

Hirschman, C., Almgren, G., 2012. University of Washington - beyond High School (UWBHS): Version 5. https://doi.org/10.3886/ICPSR33321.V5.

Jørgensen, F., Bor, A., Petersen, M.B., 2021. Compliance without fear: Individual-level protective behaviour during the first wave of the COVID-19 pandemic. Br. J. Health Psychol. 26 (2), 679-696 bjhp.12519.

Kooistra, E.B., Folmer, C.R., Kuiper, M.E., et al., 2020. Mitigating COVID-19 in a nationally representative UK sample: personal abilities and obligation to obey the law shape compliance with mitigation measures. PsyArXiv. https://doi.org/ 10.31234/osf.io/zuc23.

Martarelli, C.S., Wolff, W., 2020. Too bored to bother? Boredom as a potential threat to the efficacy of pandemic containment measures. Human. Soc. Sci. Commun. 7, 1-5.

Michie, S., van Stralen, M.M., West, R., 2011. The behaviour change wheel: a new method for characterising and designing behaviour change interventions. Implement. Sci. 6, 42.

Mongey, S., Pilossoph, L., Weinberg, A., 2020. Which Workers Bear the Burden of Social Distancing Policies? National Bureau of Economic Research, Cambridge, MA.

Murphy, K., Williamson, H., Sargeant, E., McCarthy, M., 2020. Why people comply with COVID-19 social distancing restrictions: Self-interest or duty? Aust. N. Z. J. Criminol. 53 (4), 477-496, 0004865820954484.

Painter, M., Qiu, T., 2020. Political beliefs affect compliance with COVID-19 social distancing orders. SSRN J. https://doi.org/10.2139/ssrn.3569098.

Papageorge, N.W., Zahn, M.V., Belot, M., et al., 2021. Socio-demographic factors associated with self-protecting behavior during the Covid-19 pandemic. J. Popul. Econ. 34, 691-738.

Park, C.L., Russell, B.S., Fendrich, M., Finkelstein-Fox, L., Hutchison, M., Becker, J., 2020. Americans' COVID-19 stress, coping, and adherence to CDC guidelines. J. Gen. Intern. Med. 35, 2296-2303.

Patel, J.A., Nielsen, F.B.H., Badiani, A.A., et al., 2020. Poverty, inequality and COVID-19: the forgotten vulnerable. Public Health 183, 110-111.

Peck, C.A., 1981. Relationship between Satisfaction with Housing and Quality of Life. https://core.ac.uk/download/pdf/215251197.pdf.

Perra, N., 2021. Non-pharmaceutical interventions during the COVID-19 pandemic: a review. Phys. Rep. 913, 1-52. S0370157321000624.

Pfattheicher, S., Nockur, L., Böhm, R., Sassenrath, C., Petersen, M.B., 2020. The emotional path to action: empathy promotes physical distancing and wearing of face masks during the COVID-19 pandemic. Psychol. Sci. 31, 1363-1373.
Rader, B., Scarpino, S.V., Nande, A., et al., 2020. Crowding and the shape of COVID-19 epidemics. Nat. Med. 1-6.

Raude, J., Mccoll, K., Flamand, C., Apostolidis, T., 2019. Understanding health behaviour changes in response to outbreaks: findings from a longitudinal study of a large epidemic of mosquito-borne disease. Soc. Sci. Med. 230, 184-193.

Scheier, M.F., Carver, C.S., Bridges, M.W., 1994. Distinguishing optimism from neuroticism (and trait anxiety, self-mastery, and self-esteem): a reevaluation of the life orientation test. J. Pers. Soc. Psychol. 67, 1063-1078.

Smith, B.W., Dalen, J., Wiggins, K., Tooley, E., Christopher, P., Bernard, J., 2008. The brief resilience scale: assessing the ability to bounce back. Int. J. Behav. Med. 15, 194-200.

Soto, C.J., John, O.P., 2017. The next big five inventory (BFI-2): developing and assessing a hierarchical model with 15 facets to enhance bandwidth, fidelity, and predictive power. J. Pers. Soc. Psychol. 113, 117-143.

Springborn, M., Chowell, G., MacLachlan, M., Fenichel, E.P., 2015. Accounting for behavioral responses during a flu epidemic using home television viewing. BMC Infect. Dis. 15, 21.

van der Weerd, W., Timmermans, D.R., Beaujean, D.J., Oudhoff, J., van Steenbergen, J. E., 2011. Monitoring the level of government trust, risk perception and intention of the general public to adopt protective measures during the influenza a (H1N1) pandemic in the Netherlands. BMC Public Health 11, 575.

Wang, C., Pan, R., Wan, X., et al., 2020. Immediate psychological responses and associated factors during the initial stage of the 2019 coronavirus disease (COVID19) epidemic among the general population in China. IJERPH 17, 1729.

Webster, R.K., Brooks, S.K., Smith, L.E., Woodland, L., Wessely, S., Rubin, G.J., 2020. How to improve adherence with quarantine: rapid review of the evidence. Public Health 182, 163-169.

Williams, S.N., Armitage, C.J., Tampe, T., Dienes, K., 2020. Public perceptions and experiences of social distancing and social isolation during the COVID-19 pandemic; a UK-based focus group study. BMJ Open 10, e039334.

Wright, A.L., Sonin, K., Driscoll, J., Wilson, J., 2020. Poverty and economic dislocation reduce compliance with COVID-19 shelter-in-place protocols. J. Econ. Behav. Organ. 180, 544-554.

Wright, L., Steptoe, A., Fancourt, D., 2021. Predictors of self-reported adherence to COVID-19 guidelines. A longitudinal observational study of 51,600 UK adults. Lancet Region. Health Eur. 4, 100061.

YouGov, 2021. Personal Measures Taken to Avoid COVID-19. https://yougov.co.uk/topi cs/international/articles-reports/2020/03/17/personal-measures-taken-avoidcovid-19 (accessed Sept 21, 2020).

Young, S.D., Goldstein, N.J., 2021. Applying social norms interventions to increase adherence to COVID-19 prevention and control guidelines. Prev. Med. 145, 106424.

Zajenkowski, M., Jonason, P.K., Leniarska, M., Kozakiewicz, Z., 2020. Who complies with the restrictions to reduce the spread of COVID-19?: personality and perceptions of the COVID-19 situation. Personal. Individ. Differ. 166, 110199. 